УДК 539.27

doi: 10.18101/2306-2363-2017-2-3-44-48

\title{
ИССЛЕДОВАНИЕ МАГНИТНЫХ МАТЕРИАЛОВ С ПОМОЩЬЮ ДИФРАКЦИИ НЕЙТРОНОВ
}

\author{
(С) Сангаа Делег \\ доктор физико-математических наук, профессор, \\ Институт физики и технологии, Монгольская академия наук \\ 13300, Улан-Батор, ул. Жукова, 9, Монголия \\ E-mail: sangaa@ipt.ac.mn
}

\begin{abstract}
Нейтронная дифрактометрия является эффективным и быстро развивающимся методом современных исследований. Работа посвящена конкретным возможностям метода структурных исследований в материаловедении. Особое внимание уделено применению метода нейтронной дифракции к изучению некоторых магнитных материалов. Показано использование метода нейтронной порошковой дифракции для изучения кристаллической и магнитной структуры, микроструктуры, текстурного анализа, магнитных доменов, количественного фазового анализа, напряжений, деформаций и упругих констант материалов и многих других проблем, связанных с материаловедением.
\end{abstract}

Ключевые слова: рассеяние нейтронов, кристалл, атомная и магнитная структура жесткий магнит, феррит, дифракция, материаловедение

In order to understand the properties of condensed matter at the microscopic level, it is in the first place necessary to know how elements are organized in solids and fluids. At the same time, the solution of certain problems in crystallography using X-ray structural analysis encounters great difficulties and is sometimes utterly impossible with modern experimental techniques. These problems include, among others, localization of light atoms surrounded by heavy ones, distribution of elements with close atomic numbers, isotope substitution and magnetic structures.

Neutron scattering is one of the most powerful and versatile experimental methods to study the structure and dynamics of materials on the nanometer scale.

\section{Neutron interactions}

If a slow neutron with energy $E \approx 0.02 \mathrm{eV}$ is scattered in a crystal or by a large molecule, the energy exchange could be very small: $\Delta E / E \sim \mathrm{m} / \mathrm{M}$, where $\mathrm{m}$ is the neutron mass, $\mathrm{M}$ is the crystal mass, i.e. $\sim 10^{-24}$. We can put $\Delta E=0$ and it is just this process which is known as elastic scattering. On the contrary, if $\Delta E \sim E$, the process is said to be inelastic.

According to quantum mechanics, both elastic and inelastic neutron scattering can be coherent or incoherent. Here, the regularity in phase relations of scattered waves is meant by coherence. Failures in regularity are connected with randomness in isotope distribution and mutual nucleus and neutron spin orientation.

Finally, depending on the interaction mode, neutron scattering can be classified as nuclear or magnetic scattering. The first one takes place, if the neutron interacts with the atomic nucleus; the second one is realized after the interaction between neutron and magnetic moment of an atom. Nuclear scattering always occurs, while magnetic scattering is added to nuclear scattering if the atom has unpaired electrons or orbital magnetic moment. 
In principle, each mode of scattering (there are eight altogether, Figure 1. could be utilized for realization of some particular experiment. For high-pressure studies the elastic coherent nuclear or elastic coherent magnetic scattering are used as a rule [1].

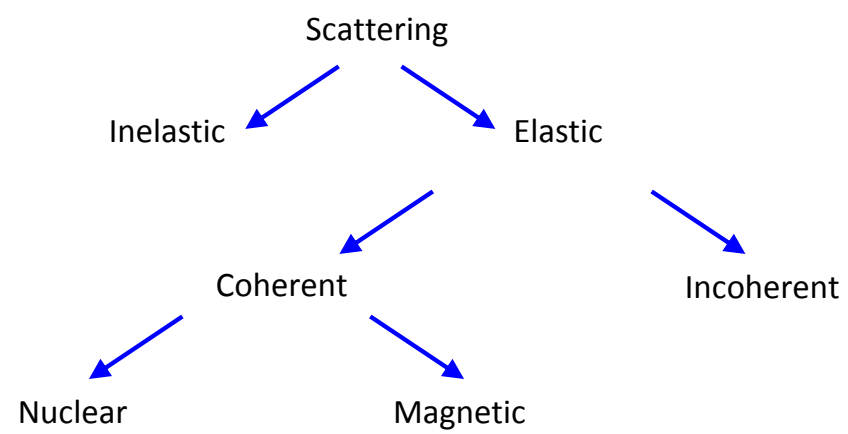

Fig. 1. Modes of slow neutron scattering by matter.

If one wants to obtain data about nuclear (magnetic) structure the elastic coherent nuclear (magnetic) scattering must be used.

\section{Neutron spectrometers}

Neutron spectrometers for elastic scattering can be roughly divided into three groups: diffractometers, small angle scattering (SANS) spectrometers and reflectometers. Diffractometers are used for experiments with single- or polycrystals for measuring Bragg scattering (diffraction peaks). With SANS spectrometer, the intensity in the range of small $\left(<10^{\circ}\right)$ angles is measured for analysis of large $(\mathrm{R}>>\lambda)$ inhomogeneities: molecules in a solvent, pores in a matrix. With reflectometers, the reflection or scattering from external or internal interfaces can be measured, which is important for studies of thin films or multilayers.

For each spectrometer data acquisition can be organized either with monochromatic incident neutron beam $(\lambda=$ const technique), or with a polychromatic ("white") beam (time-of-flight technique). The first one is used at steady-state reactors; the second one is natural for pulsed neutron sources [2].

\section{JINR and IBR-2 pulse reactor}

The Joint Institute for Nuclear Research (JINR) is an international intergovernmental organization and was established in 1956. The Institute have 18 Member countries and Mongolia is one of oldest Member country. The main areas of research at JINR are Particle Physics, Nuclear Physics and Condensed Matter Physics. The IBR-2 pulse reactor at JINR commissioned in 1984 produces the highest currently available thermal neutron flux amounting to $10^{16}$ neutron $\mathrm{cm}^{-2}$ $\mathrm{s}^{-1}$. Another characteristic feature of the IBR-2 reactor is the large neutron pulse duration ( $220 \mathrm{~ms}$ for thermal neutrons). This feature has until recently been regarded as a drawback. However, the development of the experimental technique 
on the IBR-2 reactor has demonstrated that modern instruments provide resolution comparable with that of the best pulsed sources for both elastic and inelastic scattering [3].

\section{Neutron diffraction study of crystal and magnetic structures of $\left(\operatorname{Mg}_{\mathrm{x}}\left(\mathrm{Cu}_{1-\mathrm{x}}\right)\right.$ $\mathrm{Fe}_{2} \mathrm{O}_{4}$ ferrite}

(With H. Hirazawa, Department of Environmental Materials Engineering, National Institute of Technology, 792-8580 Niihama, Japan)

The $\left(\mathrm{Mg}_{\mathrm{x}} \mathrm{Cu}_{1-\mathrm{x}}\right) \mathrm{Fe}_{2} \mathrm{O}_{4}$ ferrite spinel ferrite powders have been prepared by solid state reaction technique in the National Institute of Technology, Niihama, Japan. Bulk ferrites remain a key group of magnetic materials, while nanostructured ferrites show a dramatic promise for applications in even significantly wider fields.

Powder magnetic materials capable of high heat generation in an AC magnetic field have been investigated for application the thermal coagulation therapy of cancer tumors [4]. Crystal and magnetic structures were studied using the time-offlight (TOF-method) measurement in Frank Laboratory of Neutron Physics, JINR, Dubna, Russia on High-Resolution Fourier Diffractometer at temperatures $\mathrm{T}=25$, $150,300,400$ and $480^{\circ} \mathrm{C}$ (fig. 2).

$\mathrm{MgFe}_{2} \mathrm{O}_{4}$ sample exhibits cubic (space group $\mathrm{Fd}-3 \mathrm{~m}$ ), fully inverse spinel (inversion parameter $\mathrm{x} \approx 1$ ) and ferrimagnetic structure at room temperature. The lattice parameter increases linearly with heating, while A-O and B-O bond distances are almost constant. The temperature of ordered magnetic moments in octahedral and tetrahedral sites is conventional with $T_{\mathrm{C}} \approx 450^{\circ} \mathrm{C}$.

\section{Neutron diffraction study of the hard magnetic materials $\mathrm{Nd}_{2} \mathrm{Fe}_{14} \mathrm{~B}$ doped by Dy}

(With Y. Tsugita, National Institute of Technology, 792-8580 Nihama, Japan)

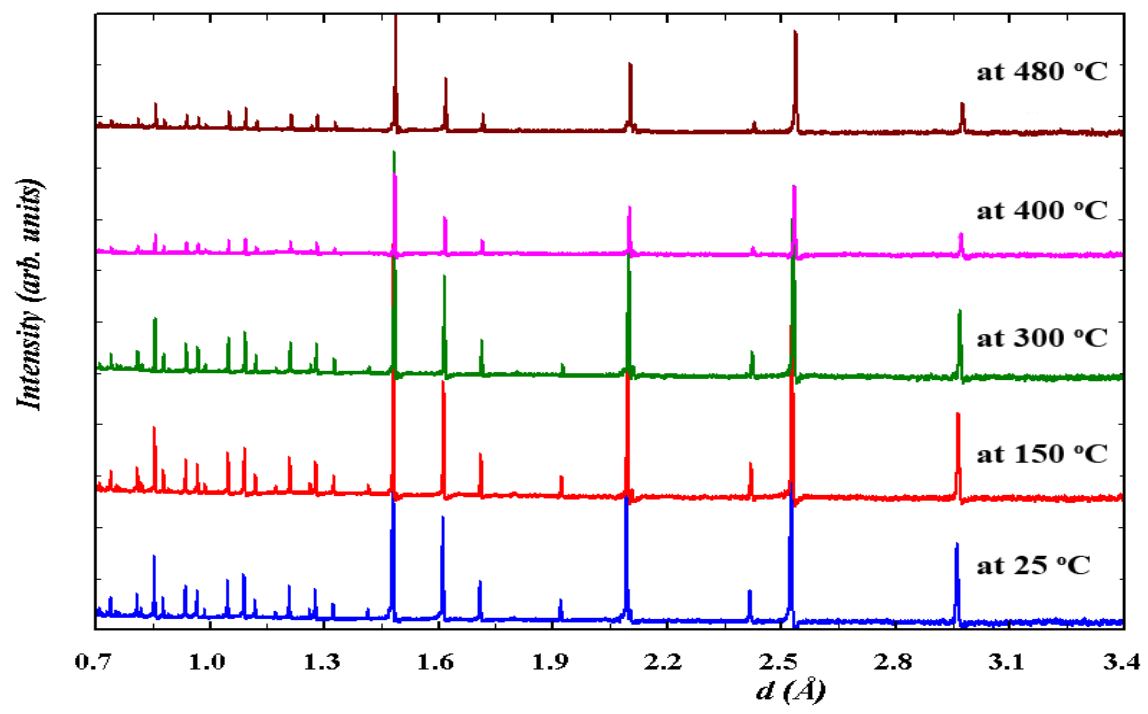

Fig. 2. Neutron diffraction patterns of $\mathrm{MgFe}_{2} \mathrm{O}_{4}$ measured at various temperatures (from room temperatures to $480^{\circ} \mathrm{C}$ ). At higher 


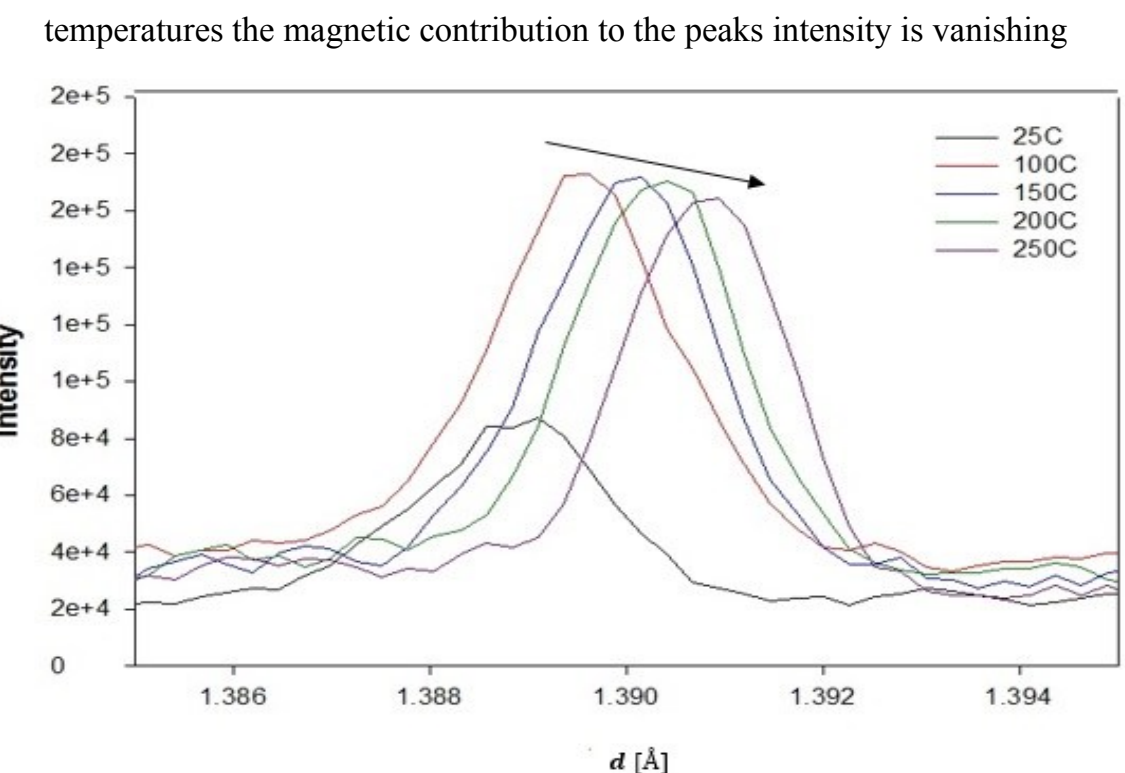

Fig. 3. Relationship of d-spacing and intensity at $1.39 \AA$ of the sintered $\mathrm{Nd}_{2} \mathrm{Fe}_{14} \mathrm{~B}$

The main purpose of our work is to study the crystal structure and magnetic properties of $\mathrm{Nd}-\mathrm{Fe}-\mathrm{B}$ magnet system containing rare earth elements by neutron diffraction method. In order to study microstructure of substance in the solid state, it requires determination of the parts of the microstructures in the material. This study was performed on the time-of-flight (TOF-method) measurement in Frank Laboratory of Neutron Physics, JINR, Dubna, Russia. The bulk sample neither with or without Ni-plating is heated at $100,150,200$ and $250^{\circ} \mathrm{C}$ (with $25^{\circ} \mathrm{C}$ ) under an atmospheric condition, because the neutron diffraction patterns will be used for investigating the effect of temperature. By neutron diffraction method we obtained the effects of temperature depending on Nd-Fe-B material, type of strong magnetism [5]. Fig. 3 shows the relationship of d-spacing and intensity at $1.39 \AA$ of the sintered $\mathrm{Nd}_{2} \mathrm{Fe}_{14} \mathrm{~B}$ magnet. The trend of peaks of intensity decreases depending on heating temperature.

It is observed that the peak intensity shift with $d$ increase depending on heating temperature.

This shift is related to $\mathrm{Nd}_{2} \mathrm{Fe}_{14} \mathrm{~B}$, which is main structure of $\mathrm{Nd}-\mathrm{Fe}-\mathrm{B}$ magnetic system and the interactive between the grain bounder and the node point. The atomic form and structure factor of $\mathrm{Nd}_{2} \mathrm{Fe}_{14} \mathrm{~B}$ magnetic materials were calculated using MathLab program.

\section{Conclusion}

TOF neutron diffraction method has been demonstrated that crystal and magnetic structures, microstructures, texture analysis, magnetic domain, quantitative phase analysis, stresses, strains, and elastic constants and much more problems for materials sciences are solving by neutron powder diffraction. 


\section{References}

1. Kisi E. H., Howard Ch. J. Applications of neutron powder diffraction. - Oxford University Press, 2008. - $464 \mathrm{p}$.

2. Aksenov V. L., Balagurov A. M. Neutron diffraction on pulsed sources // Phys. Usp. - 2016. - V. 59, № 3. - P. 279-303.

3. http://www.jinr.ru/main-en/

4. Utsunomiya S., Hirazawa H., Aono H., Naohara T., Maehara T., Watanabe Y. Heat generation ability of nanosized $\mathrm{Mg}_{1-\mathrm{x}} \mathrm{Cu}_{\mathrm{x}} \mathrm{Fe}_{2} \mathrm{O}_{4}$ ferrite in an $\mathrm{AC}$ magnetic field // J. Magn. Soc. Jpn. — 2013. - V. 37. - P. 291-294.

5. Hishigdemberel I., Sangaa D., Tsugita Y. Neutron diffraction study of the hard magnetic materials // Annual proceeding of IPT. — 2015. — № 42. — P. 82.

\section{NEUTRON DIFFRACTION STUDY OF MAGNETIC MATERIALS}

Sangaa Deleg

doctor of Physical and Mathematical Sciences, Professor, Institute of Physics and Technology, Mongolian Academy of Sciences 13300, Ulaanbaatar, Jukov Str., 9, Byanzurkh dist., Mongolia

E-mail: sangaa@ipt.ac.mn

Neutron time-of-flight diffractometry provides an effective and rapidly developing method for current neutron diffraction studies. The article it devoted to specific potentialities of the method for structural studies in material science. Special attention is paid to the application of neutron diffraction method to study some magnetic materials. Use of the method of neutron powder diffraction to study crystal and magnetic structure, microstructure, texture analysis, magnetic domains, quantitative phase analysis, stresses, strains, and elastic constants of materials, and many other problems related to materials science has beed revealed.

Keywords: neutron scattering, crystal, atomic and magnetic structure, hard magnetic, ferrite, diffraction, material science. 